\title{
Atividade Física e Saúde Mental do Idoso
}

Flávia Gomes de Melo Coelho

Jair Sindra Virtuoso Júnior
Rev Bras Ativ Fis Saúde p. 663-664

DO

http://dx.doi.org/10.12820/rbafs.v.19n5p663

1 Universidade Federal do Triângulo Mineiro, Programa de Pós-Graduação em Educação

Física, Uberaba, Minas Gerais, Brasil
A saúde mental pode ser entendida como uma gama extensa de atividades relacionadas ao componente do bem estar mental incluso na própria definição de saúde como "um estado de completo bem-estar físico, mental e social e não meramente a ausência de doença". Apesar da caracterização abrangente do que se trata saúde mental, o declínio cognitivo e os sintomas depressivos se destacam como transtornos mentais de forte interação entre si podendo ser beneficiado com a prática de atividade física.

Há estimativas de que $10 \%$ a $30 \%$ da população idosa brasileira possui algum comprometimento das funções cognitivas e/ou apresenta sintomas depressivos. Entretanto, o diagnóstico ou a triagem de componentes da saúde mental são altamente sensíveis a alterações etárias, disparidades sociodemográficas e do método utilizado na avaliação.

Nos últimos anos os efeitos neuroprotetores da atividade física têm ganhado destaque na área temática de saúde mental. A primeira evidência do mecanismo pelo qual a atividade física poderia modificar as funções cognitivas foi mostrada pelo estudo clássico de Van Praag et al. ${ }^{2}$, no qual, animais adultos submetidos à atividade física voluntária apresentaram um aumento da neurogênese e da proliferação de células no hipocampo. A partir deste trabalho, houve um crescente aumento de estudos em animais e em humanos.

Os mecanismos neurofisiológicos da atividade física que podem beneficiar a saúde mental incluem: a liberação de neurotransmissores, o aumento do fluxo sanguíneo e da vascularização cerebral e o aumento na síntese dos fatores neurotróficos, como o BDNF, que favorecem a neurogênese e a plasticidade cerebral.

Os benefícios da atividade física no desempenho cognitivo e na diminuição dos sintomas depressivos podem ser desenvolvidos nos três níveis de intervenção: primária, secundária e terciária. A intervenção primária tem com objetivo proteger a saúde e evitar o aparecimento de doenças - neste sentido, manter-se ativo desencadeia benefícios psicológicos e emocionais que protege e promove a saúde mental e diminui o risco de declínio cognitivo, demência e depressão; o nível secundário tem como objetivo identificar precocemente a patologia quando ainda é assintomática e tratá-la, tentando estabelecer novamente o estado normal - o comprometimento cognitivo leve (reflete um estado de transição entre o declínio cognitivo advindo do envelhecimento normal e a demência) e a depressão podem ser revertidos com atividades físicas; o nível terciário tem como objetivo evitar a progressão da doença já instalada, tratando os sintomas da mesma - neste caso o exercício físico é considerado como uma alternativa não farmacológica que influencia positivamente os sintomas cognitivos, comportamentais e motores da demência, da doença de $\mathrm{Al}$ zheimer e da doença de Parkinson e pode atenuar a progressão destas doenças.

A elaboração e implementação de novas políticas públicas voltadas à promoção de saúde mental e à reabilitação das doenças mentais devem ser reali- 
zadas, como a criação de programas de atividade física em Centros de Atenção Psicossocial (CAPS). Os CAPS são promovidos pelo Ministério da Saúde e têm com objetivo acolher os pacientes com transtornos mentais e estimular a integração familiar e social. Sabe-se que a atuação do profissional de Educação Física nos CAPS ainda é escassa, mas é necessária, já que este profissional pode ser incluído na equipe multidisciplinar responsável pela instituição. Assim, faz se necessário à realização de estudos em instituições como a CAPS e ações voltadas à formação/especialização dos profissionais de Educação Física para atuar nos serviços de saúde mental.

\section{REFERÊNCIAS}

1. World Health Organization. Comprehensive Mental Health Action Plan 2013-2020. Geneva: World Health Organization, 2013. [citado 2014 out 20] Disponível em: http:// www.who.int/mental_health/publications/action_plan/en/

2. Van Praag H, Christie BR, Sejnowski TJ, Gage FH. Running enhances neurogenesis, learning, and long-term potentiation in mice. Proc Natl Acad Sci U S A. 1999;96:13427-31.

ENDEREÇO PARA

CORRESPONDÊNCIA

Núcleo de Estudos em Atividade

Física \& Saúde - Neafisa/UFTM

Av. Tutunas, 490, Tutunas

38061-500 Uberaba, MG, Brasil

E-mail: jairlaef.uftm.edu.br 